\title{
Impact of meteorological anomalies in the 2003 summer on Gross Primary Productivity in East Asia
}

\author{
N. Saigusa ${ }^{1}$, K. Ichii ${ }^{2}$, H. Murakami ${ }^{3}$, R. Hirata ${ }^{4}$, J. Asanuma ${ }^{5}$, H. Den ${ }^{6}$, S.-J. Han ${ }^{7}$, R. Ide ${ }^{1}$, S.-G. Li ${ }^{8}$, T. Ohta ${ }^{9}$, \\ T. Sasai ${ }^{10}$, S.-Q. Wang ${ }^{8}$, and G.-R. Yu ${ }^{8}$ \\ ${ }^{1}$ Center for Global Environmental Research, National Institute for Environmental Studies, Tsukuba 305-8506, Japan \\ ${ }^{2}$ Faculty of Symbiotic Systems Science, Fukushima University, Fukushima 960-1296, Japan \\ ${ }^{3}$ Earth Observation Research Center, Japan Aerospace Exploration Agency, Tsukuba 305-8505, Japan \\ ${ }^{4}$ Graduate School of Agriculture, Hokkaido University, Sapporo 060-8589, Japan \\ ${ }^{5}$ Terrestrial Environment Research Center, University of Tsukuba, Tsukuba 305-8577, Japan \\ ${ }^{6}$ Academic Express, Inc., Tsukuba 305-0035, Japan \\ ${ }^{7}$ Institute of Applied Ecology, Chinese Academy of Sciences, Shenyang 110016, China \\ ${ }^{8}$ Key Lab of Ecosystem Network Observation and Modeling, Institute of Geographic Sciences and Natural Resources \\ Research, Chinese Academy of Sciences, Beijing 100101, China \\ ${ }^{9}$ Graduate School of Bioagricultural Sciences, Nagoya University, Nagoya 464-8601, Japan \\ ${ }^{10}$ Graduate School of Environmental Studies, Nagoya University, Nagoya 464-8601, Japan
}

Received: 30 June 2009 - Published in Biogeosciences Discuss.: 8 September 2009

Revised: 8 January 2010 - Accepted: 28 January 2010 - Published: 15 February 2010

\begin{abstract}
Northern Eurasia experienced anomalous weather conditions in the 2003 summer. We examined how forest ecosystems responded to the meteorological anomalies during the period using the dataset collected at flux monitoring sites in Asia, including a boreal forest in Mongolia, temperate forests in China and Japan, and a sub-tropical forest in China, as well as the dataset from satellite remote sensing. From July to August 2003, an active rain band stayed in the mid-latitude in East Asia for an unusually long period. Under the influence of the rain band, the Gross Primary Production (GPP), of temperate forests was 20-30\% lower in the 2003 summer than in other years due to significant reduction in the Photosynthetic Photon Flux Density (PPFD). The GPP of a cool-temperate forest in the north of the rain band was slightly enhanced by the higher PPFD; however, the GPP of a sub-tropical forest located in the south of the rain band was reduced by drought stress due to extremely hot and dry conditions. The correlation coefficients for the year-to-year changes in the PPFD and GPP during mid-summer were calculated, and the spatial distribution was examined. The spatial pattern of the PPFD was calculated by satellite data, and that of the GPP was estimated by a regression-type model,
\end{abstract}

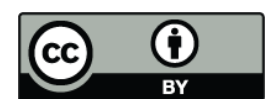

Correspondence to: N. Saigusa (n.saigusa@nies.go.jp) which was trained and tested by ground observation data. The correlation was positive in the mid- and high-latitudes since light was an essential factor of the summer GPP. On the other hand, a negative correlation appeared in the lower latitudes, suggesting that the water limitation was much more important than the PPFD in the region. Our study illustrated that the integration of flux data from wide areas by combining satellite remote sensing data can help us gain an understanding of the ecosystem responses to large-scale meteorological phenomena.

\section{Introduction}

East Asia is a part of the monsoon climate region in the world. There are many characteristic weather systems in different seasons, such as an early summer rainy season ("Baiu" in Japanese, "Meiyu" in Chinese, and "Changma" in Korean), tropical cyclones (typhoons) in summer and fall, and cold surges by the northwesterly winter monsoon (Yoshino, 1965, 1966). The early summer rainy season in East Asia provides a sufficient water supply to terrestrial ecosystems over Japan, Korea, and eastern China and maintains the high productivity of the temperate vegetation in the region. The intensity and duration of the early summer rainy season, which are determined by the air-sea-land interactions

Published by Copernicus Publications on behalf of the European Geosciences Union. 
over the Pacific Ocean and Eurasia, have a large seasonal and year-to-year variability (Matsumoto, 1992; Tian and Yasunari, 1998). This variability is a major focus of research in agriculture, disaster prevention, and estimations of carbon and water cycles in East Asia (Kitoh and Uchiyama, 2006).

Recent studies using flux measurement networks in Asia have shown that the year-to-year changes in annual net ecosystem $\mathrm{CO}_{2}$ exchanges are controlled by different key factors in different biomes. In humid temperate forests in East Asia, the key factors are the temperature and solar radiation during the growing season (Ohtani et al., 2005; Saigusa et al., 2005; Yu et al., 2008), which vary year-to-year in response to the timing of the early summer rainy seasons. In the Tibetan alpine grassland, important factors are the temperature and biomass increment during the growing season (Kato et al., 2006). In sub-tropical and tropical forests in southeastern China and in Thailand, they are the length and strength of the dry season (Sun et al., 2006; Yu et al., 2008; Saigusa et al., 2008), and the El Niño/Southern Oscillation (ENSO)-related dry weather and smoke from fires are critical in a tropical peat swamp forest in Indonesia (Hirano et al., 2007).

In addition to such recent studies, more synthetic knowledge of how ecosystem functions on carbon and water cycles respond to large-scale meteorological phenomena, such as year-to-year changes in Asian monsoon circulations, would be desirable. Such information is necessary for more accurate estimations of terrestrial ecosystem processes in order to improve future climate change predictions. One of the reasons is that ongoing global warming has the potential to increase the frequency and magnitude of many extreme climatic events, including floods, droughts, tropical and other storms, and anomalous temperatures in the global scale as well as in the Asian monsoon region (Meehl and Washington, 1993; Kitoh et al., 1997; Easterling et al., 2000; Meehl and Arblaster, 2003). Such assessments are indispensable to estimate the impacts of extreme climatic events on terrestrial ecosystems. Another reason is that any of the recent climate prediction models needs to incorporate the biological feedback of terrestrial ecosystems that may play important roles in the global carbon and water cycles (Yoshikawa et al., 2008). However, we still do not understand the magnitude of the feedback, and the models have enormous uncertainties in the estimation of that feedback.

In recent years, the climate of 2003, particularly that during Northern Hemisphere summer, was exceptionally anomalous throughout the world. The summer of 2003 was very likely warmer than any other summer back to 1500 in southern Europe (Luterbacher et al., 2004), and the heat wave led to drought, crop shortfalls, and health crises in several countries (Levinson and Waple, 2004; Ciais et al., 2005). Other climatic extreme events during 2003 included wet and cold conditions as well as severe drought throughout the world. Record cold temperatures and unusual snowfalls were observed in the early summer over European Russia (Levin- son and Waple, 2004). Heavy rain and floods occurred over the West Sahara, while drought conditions were observed in the Guinea Coast and southeastern Southern Africa (Kadomura, 2005). Record wet conditions were observed across parts of the Southeast, Mid Atlantic, and East Coast of the United States (Levinson and Waple, 2004).

In the eastern parts of Eurasia from June to August 2003, the rainy season was prolonged within the latitudinal range of $30-40^{\circ} \mathrm{N}$ and longitudinal range of $100-150^{\circ} \mathrm{E}$, extending from China, Honshu, the main island of Japan, through South Korea. The rain front remained over the area for an unusually long time and brought floods in the Huai River basin $\left(31-36^{\circ} \mathrm{N} ; 112-121^{\circ} \mathrm{E}\right)$ in China (Liu et al., 2004) and a cool summer with extremely low insolation over Honshu, Japan $\left(33-41^{\circ} \mathrm{N} ; 131-142^{\circ} \mathrm{E}\right)$ (Kusunoki, 2005). On the other hand, the weather was extremely hot and dry in southeastern China (Sun et al., 2006).

The key questions in this study are as follows:

1. How meteorological anomalies in the 2003 summer affected the productivity of Asian forests both in the point scale and in the continental scale?

2. What is the essential controlling factor of the productivity, and how does it change under different climatic regions?

The data used in this study originated from tower-based $\mathrm{CO}_{2}$ flux monitoring sites and satellite remote sensing. Discussions are conducted to clarify the spatial distributions of the forest productivity in Asia and its relation to meteorological anomalies in the 2003 summer.

World Meteorological Organization defined "abnormal (weather)" as an unusual climatic phenomenon occurring only every 25 years or more. The word "anomalous (weather)" has a similar meaning; however, it is used in the broader sense in the present study.

\section{Methods}

\subsection{Ground observational sites}

Six ground observational sites were selected in East Asia, which had data of two years or more in around 2003, in order to compare the ecosystem-atmosphere $\mathrm{CO}_{2}$ exchange between different years. The sites are: a boreal larch forest in a mountainous region in Mongolia (Southern Khentei Taiga, SKT); a cool-temperate planted larch forest in Hokkaido, Japan (Tomakomai Flux Research Site, TMK); a cool-temperate mixed forest in China (Forest Ecosystem Open Research Station of Changbai Mountains, CBS); a cool-temperate birch-oak secondary forest in central Japan (Takayama Deciduous Broadleaf Forest Site, TKY); a warmtemperate mixed evergreen and deciduous forest in Japan (Seto Mixed Forest Site, SMF); and a sub-tropical planted 
pine forest in China (Qianyanzhou Experimental Station, QYZ). The locations of the study sites are shown in Fig. 1. The ecosystem type, dominant species, and approximate age are described in Table 1. The climatic conditions are presented in Table 2.

\subsection{Flux measurement and data processing}

All sites had an eddy covariance measurement system installed on a tower, which consisted of a three-dimensional sonic anemometer-thermometer, an infrared gas analyzer (IRGA) for $\mathrm{CO}_{2}$ and water vapor, and a data acquisition system. Open and/or closed-path IRGAs were utilized depending on the site. The measurement systems for each site as used in the study period are listed in Table 3.

The net ecosystem $\mathrm{CO}_{2}$ exchange (NEE) was estimated every half hour from the $\mathrm{CO}_{2}$ flux over the canopy taking into account the temporal change in $\mathrm{CO}_{2}$ storage below the height of the flux measurement system. We used quality-controlled half-hourly datasets and screened out unusual data and low nocturnal turbulent conditions on the basis of the site-specific protocols and $\mathrm{u}_{*}$-threshold values listed in Table 3 .

Nighttime and daytime data were fitted to empirical functions listed as follows (Eqs. 1-5), and the functions were used to fill observational gaps for each site. The quality control processes rejected approximately $53-75 \%$ of observed data. The gaps made by the rejected values were filled by the equations.

For nighttime, the observed nighttime NEE ( $\left.F_{\mathrm{NEE}, \text { night }}\right)$ was fitted to the equation of Lloyd and Taylor (1994):

$$
\begin{aligned}
& F_{\mathrm{NEE}, \text { night }}=F_{\mathrm{RE}} \\
& =F_{\mathrm{RE}, T_{\mathrm{ref}}} \exp \left(\frac{E_{0}}{R}\left(\frac{1}{T_{K}+T_{\mathrm{ref}}-T_{0}}-\frac{1}{T_{K}+T_{a}-T_{0}}\right)\right),
\end{aligned}
$$

where $F_{\mathrm{RE}}$ is the total ecosystem respiration rate (RE) obtained by the nighttime NEE, $F_{\mathrm{RE}, T_{\mathrm{ref}}}$ is RE at the reference temperature $T_{\text {ref }}\left(=10^{\circ} \mathrm{C}\right), E_{0}$ is the activation energy (in $\left.\mathrm{J} \mathrm{mol}^{-1}\right), R$ is the ideal gas constant $\left(=8.314 \mathrm{~J} \mathrm{~mol}^{-1} \mathrm{~K}^{-1}\right)$, and $T_{K}$ and $T_{0}$ are constants (i.e., 273.15 and $227.13 \mathrm{~K}$, respectively). The two parameters, $E_{0}$ and $F_{\mathrm{RE}, T_{\text {ref }}}$, are the regression coefficients. The air temperature was used for $T_{a}$ $\left({ }^{\circ} \mathrm{C}\right)$ at each site with the exception of CBS, where the soil temperature at $5 \mathrm{~cm}$ in depth was used because it gave better regressions (Yu et al., 2008).

For most sites, the Lloyd and Taylor equation was applied to estimate the RE; however, the soil moisture affected the $\mathrm{RE}$ significantly at QYZ due to severe seasonal droughts (Yu et al., 2006; Wen et al., 2006; Yu et al., 2008). Therefore, the temperature and soil water content were taken into account to estimate the RE at QYZ with the following equations (Wen et al., 2006; Yu et al., 2008).

$$
\begin{aligned}
& F_{\mathrm{NEE}, \text { night }}=F_{\mathrm{RE}}=F_{\mathrm{RE}, T_{\mathrm{ref}}} \exp \left(\ln \left(Q_{10}\right) \frac{\left(T_{a}-T_{\mathrm{ref}}\right)}{10}\right), \\
& Q_{10}=a+b T_{a}+c S_{w}+d S_{w}^{2},
\end{aligned}
$$

where $Q_{10}$ is the temperature sensitivity of respiration, $T_{a}$ is the air temperature, $S_{w}$ is the volumetric soil water content $\left(\mathrm{m}^{3} \mathrm{~m}^{-3}\right)$, and $a, b, c$, and $d$ are regression parameters.

For the daytime, the observed daytime NEE $\left(F_{\mathrm{NEE}, \text { day }}\right)$ was fitted to the following Michaelis-Menten equation for CBS and QYZ (Yu et al., 2008):

$F_{\mathrm{NEE}, \mathrm{day}}=-\frac{\phi \mathrm{PPFD} P_{\max }}{\phi \mathrm{PPFD}+P_{\max }}+R_{d}$

Here, $\phi$ is the initial slope, PPFD is the Photosynthetic Photon Flux Density, $P_{\max }$ is the maximum level of Gross Primary Production (GPP) at light saturation, and $R_{d}$ is the intercept. The three parameters $\phi, P_{\max }$, and $R_{d}$ are regression coefficients.

The daytime NEE for SKT, TMK, TKY, and SMF was fitted to the following non-rectangular hyperbola relationship (Thornley, 1976) because it gave better regressions:

$F_{\mathrm{NEE}, \text { day }}$
$=\frac{-\phi \mathrm{PPFD}-P_{\max }+\sqrt{\left(\phi \mathrm{PPFD}+P_{\max }\right)^{2}-4 \phi \mathrm{PPFD} \theta P_{\max }}}{2 \theta}+R_{d}$,

where $\theta(=0.9)$ is a parameter of convexity. The three parameters $\phi, P_{\max }$, and $R_{d}$ are regression coefficients.

Gaps in the nighttime and daytime NEE were filled using Eqs. (1) to (5) as the functions of the temperature, soil water content, and PPFD; while small gaps $(<2-3 \mathrm{~h})$ were linearly interpolated. The GPP was calculated by GPP $=-\mathrm{NEE}+$ $\mathrm{RE}$. The temperature dependence of RE in the daytime was assumed to be equal to the nighttime estimation, and the daytime RE was calculated by Eq. (1) or Eq. (2) using the daytime temperature. Detailed descriptions of gap filling and flux partitioning have been presented by Hirata et al. (2008) for SKT, TMK, TKY, and SMF and by Yu et al. (2008) for CBS and QYZ.

The estimation of RE is one of the most critical sources of uncertainty at many forest sites. Recent studies in Asian forest sites showed that the uncertainty in the nighttime correction was quite high especially in warm regions such as tropical forests (Hirata et al., 2008; Saigusa et al., 2008), which had tall canopies and high respiratory activities. Effective and standardized protocols for quality-control and gapfilling for various forest ecosystems in Asia have not been established yet. Therefore, we applied site-specific method based on different functions (Eqs. 1-5) in order to simulate realistic nighttime and daytime NEE for each site.

The gap-filled datasets of the NEE, RE, and GPP were used from 2003 to 2005 for SKT and SMF and from 2003 to 2004 for CBS and QYZ, since the measurements started in 2002 or in 2003 at these sites. The data from 2001 to 2003 were used for TMK and TKY because of data availability. The observation at TMK was terminated in September 2004, since the towers and most trees collapsed as a result of strong typhoon winds. At TKY, the GPP was unusually low in 2004 due to unexpected defoliation caused by severe 
Table 1. Description of the study sites.

\begin{tabular}{|c|c|c|c|c|c|c|c|c|c|}
\hline Code & Site name & Country & $\begin{array}{l}\text { Location } \\
\left({ }^{\circ} \mathrm{N},{ }^{\circ} \mathrm{E}\right)\end{array}$ & $\begin{array}{r}\text { Elevation } \\
(\mathrm{m})\end{array}$ & $\begin{array}{l}\text { Ecosystem } \\
\text { type }\end{array}$ & Dominant species & $\begin{array}{l}\text { Age } \\
\text { (year) }\end{array}$ & $\begin{array}{c}\text { Canopy } \\
\text { height }(\mathrm{m})\end{array}$ & References \\
\hline SKT & $\begin{array}{l}\text { Southern Khentei } \\
\text { Taiga }\end{array}$ & Mongolia & $\begin{array}{l}48^{\circ} 21^{\prime} \\
108^{\circ} 39^{\prime}\end{array}$ & 1630 & $\mathrm{DC}$ & Larix sibirica & $70-300$ & 20 & Li et al. (2005) \\
\hline TMK & $\begin{array}{l}\text { Tomakomai Flux } \\
\text { Research Site }\end{array}$ & Japan & $\begin{array}{l}42^{\circ} 44^{\prime} \\
141^{\circ} 31^{\prime}\end{array}$ & 140 & DC & Larix kaempferi & 45 & 16 & $\begin{array}{l}\text { Hirano et al. (2003); } \\
\text { Hirata et al. (2007) }\end{array}$ \\
\hline CBS & $\begin{array}{l}\text { Forest Ecosystem Open } \\
\text { Research Station of } \\
\text { Changbai Mountains }\end{array}$ & China & $\begin{array}{l}42^{\circ} 24^{\prime} \\
128^{\circ} 05^{\prime}\end{array}$ & 738 & MX & $\begin{array}{l}\text { Pinus koraiensis, } \\
\text { Tilia amurensis, } \\
\text { Acer mono, } \\
\text { Quercus mongolia, } \\
\text { Fraxinus mandshurica }\end{array}$ & $\sim 200$ & 26 & $\begin{array}{l}\text { Yu et al. (2006; 2008); } \\
\text { Zhang et al. (2006) }\end{array}$ \\
\hline TKY & $\begin{array}{l}\text { Takayama Deciduous } \\
\text { Broadleaf Forest Site }\end{array}$ & Japan & $\begin{array}{l}36^{\circ} 08^{\prime} \\
137^{\circ} 25^{\prime}\end{array}$ & 1420 & DB & $\begin{array}{l}\text { Betula ermanii, } \\
\text { Quercus crispula }\end{array}$ & 50 & $15-20$ & Saigusa et al. (2002) \\
\hline SMF & Seto Mixed Forest Site & Japan & $\begin{array}{l}35^{\circ} 15^{\prime} \\
137^{\circ} 04^{\prime}\end{array}$ & 205 & MX & $\begin{array}{l}\text { Quercus serrata, } \\
\text { Evodiopanax innovans, } \\
\text { Ilex pedunculosa, } \\
\text { Symplocos prunifolia, } \\
\text { Castanopsis sieboldii, } \\
\text { Pines densiflora }\end{array}$ & $70-80$ & 9 & $\begin{array}{l}\text { Matsumoto et al. } \\
\text { (2008a, 2008b) }\end{array}$ \\
\hline QYZ & $\begin{array}{l}\text { Qianyanzhou } \\
\text { Experimental Station }\end{array}$ & China & $\begin{array}{l}26^{\circ} 44^{\prime} \\
115^{\circ} 03^{\prime}\end{array}$ & 102 & $\mathrm{EC}$ & $\begin{array}{l}\text { Pinus massoniana, } \\
\text { Pinus elliottii, } \\
\text { Cunninghamia lanceo- } \\
\text { lata }\end{array}$ & 23 & 12 & $\begin{array}{l}\text { Yu et al. }(2006,2008) \text {; } \\
\text { Wen et al. }(2006)\end{array}$ \\
\hline
\end{tabular}

Description of ecosystem type: DC deciduous coniferous forest; MX mixed evergreen and deciduous forest; DB deciduous broadleaved forest; EC evergreen coniferous forest.

Table 2. Climatic conditions and period of meteorological observations.

\begin{tabular}{|c|c|c|c|c|c|}
\hline Code & $\begin{array}{r}\text { Annual mean } \\
\text { air temperature } \\
\left({ }^{\circ} \mathrm{C}\right)\end{array}$ & $\begin{array}{r}\text { Annual } \\
\text { precipitation } \\
(\mathrm{mm})\end{array}$ & Period & Climatic zone & References \\
\hline SKT & -2.7 & 296 & 1993-2002 & cold continental & Li et al. (2005) \\
\hline TMK & 6.2 & 1040 & 2001-2003 & cool-temperate & Hirata et al. (2007) \\
\hline CBS & 3.6 & 695 & 1982-2003 & cool-temperate & Guan et al. (2006) \\
\hline TKY & 6.4 & 2300 & 1994-2002 & cool-temperate & Saigusa et al. (2005) \\
\hline SMF & 15.4 & 1565 & 1971-2000 & warm-temperate & Matsumoto et al. (2008a) \\
\hline QYZ & 17.9 & 1485 & 1985-2004 & sub-tropical & Wen et al. (2006) \\
\hline
\end{tabular}

Table 3. Systems for eddy covariance measurements and period of data analyses.

\begin{tabular}{|c|c|c|c|c|c|c|}
\hline Code & $\begin{array}{l}\text { Height } \\
\text { (m) }\end{array}$ & Sonic anemometer & IRGA & $\begin{array}{l}\mathrm{u}^{*} \text { threshold } \\
\left(\mathrm{ms}^{-1}\right)\end{array}$ & Period & References \\
\hline SKT & 30 & SAT-540, Kaijo* 1 & LI-7500, LI-COR $* 3$ & 0.3 & $2003-2005$ & Li et al. (2005) \\
\hline TMK & 27 & DA600-3TV, Kaijo* 1 & LI-6262, LI-COR* 3 & 0.3 & $2001-2003$ & Hirata et al. (2007) \\
\hline CBS & 40 & CSAT-3, Campbell* 2 & LI-7500, LI-COR* 3 & $\begin{array}{l}0.05 \\
\text { (non-growing } \\
\text { period) } \\
<0.17 \\
\text { (growing period) }\end{array}$ & 2003-2004 & Yu et al. (2008) \\
\hline TKY & 25 & DA600-3T, Kaijo* 1 & LI-6262, LI-COR* 3 & 0.5 & 2001-2003 & Saigusa et al. (2005) \\
\hline SMF & 19 & DAT540, Kaijo* 1 & LI-7500, LI-COR* 3 & 0.3 & 2003-2005 & Matsumoto et al. (2008a) \\
\hline QYZ & 40 & CSAT-3, Campbell*2 & LI-7500, LI-COR* 3 & 0.2 & 2003-2004 & Yu et al. (2008) \\
\hline
\end{tabular}

* 1 KAIJOSONIC Corporation, Tokyo, Japan

* 2 Campbell Scientific, Inc., Logan, UT, USA

* 3 LI-COR, Inc., Lincoln, NE, USA 


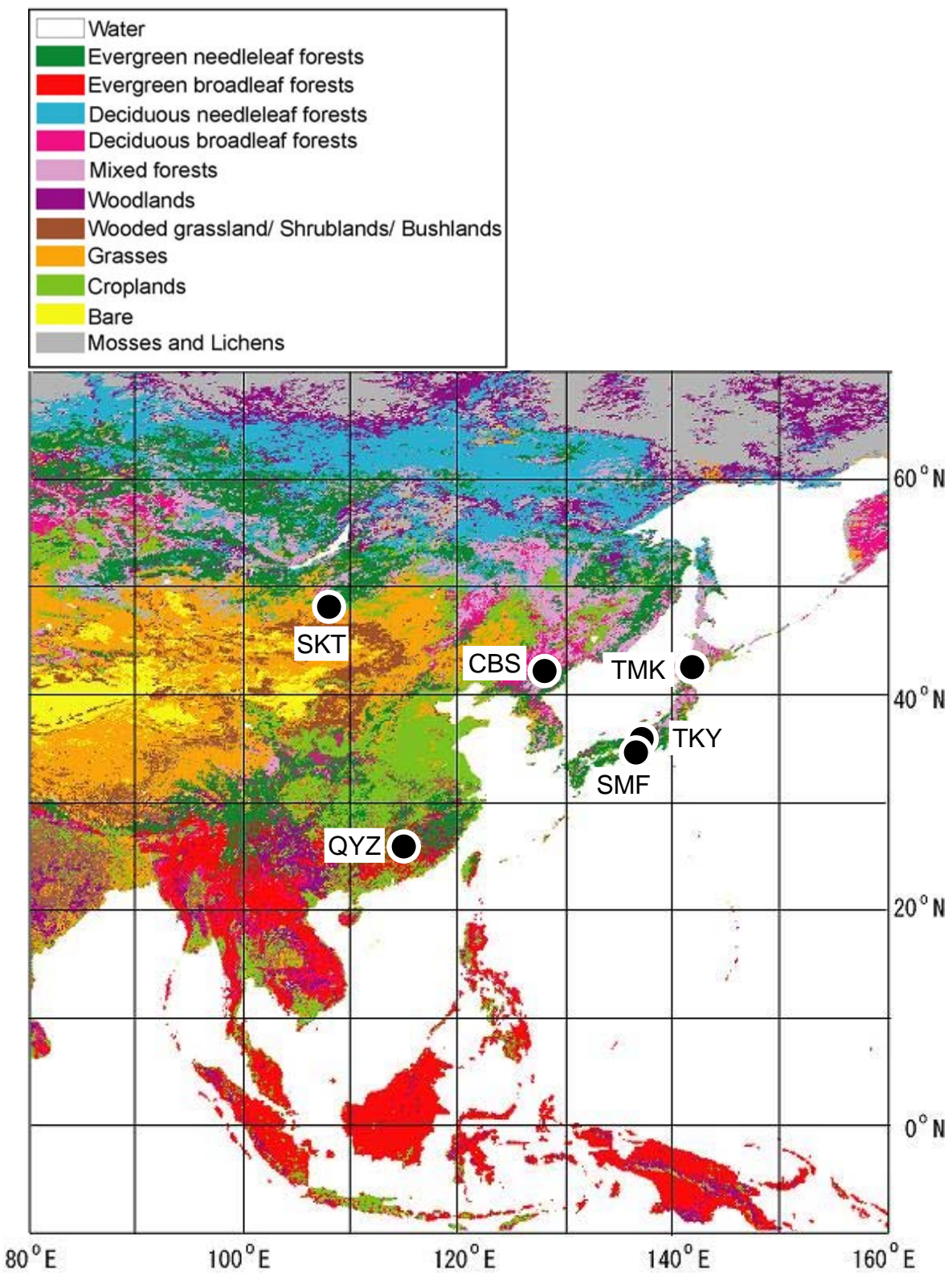

Fig. 1. Location of study sites in East Asia on a land classification map illustrated according to De Fries et al. (1998).

typhoon winds, and the data observed in and after 2004 were not used for this study to avoid the influence of disturbance.

\subsection{PPFD based on satellite remote sensing}

To show the spatial distribution of the PPFD and its influence on photosynthetic productivity in East Asia, we estimated the PPFD using channels in 400-700 nm of the MODerate resolution Imaging Spectroradiometer (MODIS) carried by the NASA's Earth Observing System satellites, Terra and Aqua, and the Sea-viewing Wide Field-of-view Sensor (SeaWiFS) carried by the SeaStar satellite. The PPFD data were produced as a daily mean at $25 \mathrm{~km}$ resolution for the period from
2001 to 2006 and then monthly averaged. The MODIS products were used to estimate PPFD satisfactorily only after July 2002. Therefore we used SeaWiFS from January 2001 to June 2002, and MODIS from July 2002 to December 2006.

The method was originally developed by Frouin and Murakami (2007) for the estimation of the PPFD over the ocean surface from Advanced Earth Observing Satellite II (ADEOS-II) Global Imager (GLI) data. The planetary atmosphere was simplified as a clear atmosphere positioned above a cloud layer taking atmospheric absorption (due to the ozone and water vapor) into account. The estimation of the land PPFD requires land surface reflectance to separate atmospheric backscattered lights from the top-of-atmosphere 
(TOA) radiance. We derived monthly land-surface reflectance by using aerosol optical thickness at $412 \mathrm{~nm}$ and assuming the tropospheric aerosol model. The optical thickness is derived using the TOA and land-surface reflectance at $412 \mathrm{~nm}$, which was empirically estimated by the Normalized Difference Vegetation Index (NDVI).

The PPFD estimated by satellite was converted to the daily value by using calculated diurnal cycle of the solar zenith angle and the satellite-observed instantaneous atmospheric conditions. The algorithm had been verified with in situ measurements from moored buoys over oceans; the root mean square difference (RMSD) by the average PPFD was 23\%, $14 \%$, and $10 \%$ on daily, weekly, and monthly time scales, respectively (Frouin and Murakami, 2007). We validated the land PPFD using the three ground study sites, SKT, TMK, and TKY. Figure 2a, $b$ show that the satellite PPFD satisfactorily estimated daily and monthly PPFD. The error ratios (RMSD / in situ average) of the monthly data are $21 \%, 15 \%$, and $7 \%$ at SKT, TMK, and TKY respectively (Fig. 2b). Relatively large errors (underestimation) in SKT samples were found mainly in the winter-spring seasons, when the area was covered by snow, which is easily mistaken for clouds from a satellite. The satellite PPFD agreed well with the in situ data within about $1 \%$ bias at the other two sites.

\subsection{GPP in continental scale}

We used a machine-learning technique for regressions to obtain spatio-temporal GPP variations by combining satellite remote sensing data and ground observation data as described by Yang et al. (2007). The method is based on the regression-type support vector machine (SVM), which transforms a nonlinear regression into a linear regression by mapping the original low-dimensional input space to a higherdimensional feature space using kernel functions (e.g., Cristianini and Shawe-Taylor, 2000), with inputs of incoming surface solar radiation (Rad), satellite-based land surface temperature (LST), satellite-based enhanced vegetation index (EVI), and land cover (Yang et al., 2007). The method was originally assessed at more than 30 Ameriflux sites over the continental United States and extended spatially using satellite data. The method was found to be effective for predicting spatio-temporal GPP patterns with acceptable accuracy (e.g., $R^{2}=0.72$ and root mean square error $(\mathrm{RMSE})=$ $1.84 \mathrm{gC} \mathrm{m}^{-2}$ day $^{-1}$; Yang et al., 2007).

The SVM analysis consists of three main steps for model tuning and testing. First, the SVM model parameters $(\mathrm{C}$ : cost of errors, $\varepsilon$ : width of an insensitive error band, and $\sigma$ : kernel parameter) were obtained from a training set. Second, with the obtained parameters for the model structure, we trained the model. Last, we evaluated the model based on a test set. More details regarding the methods are described in Yang et al. (2006, 2007), and Ichii et al. (2009). After evaluation, the model was employed to obtain the spatio-temporal vari- (a) Daily-base

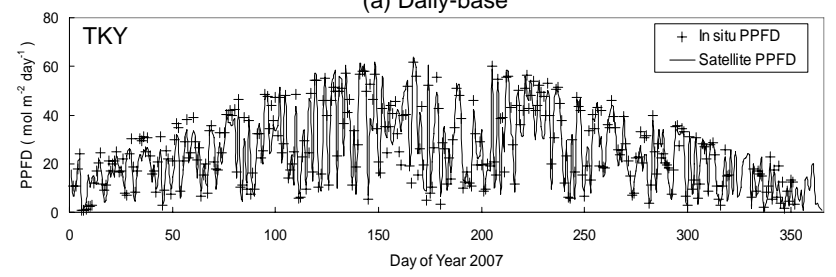

(b) Monthly-base

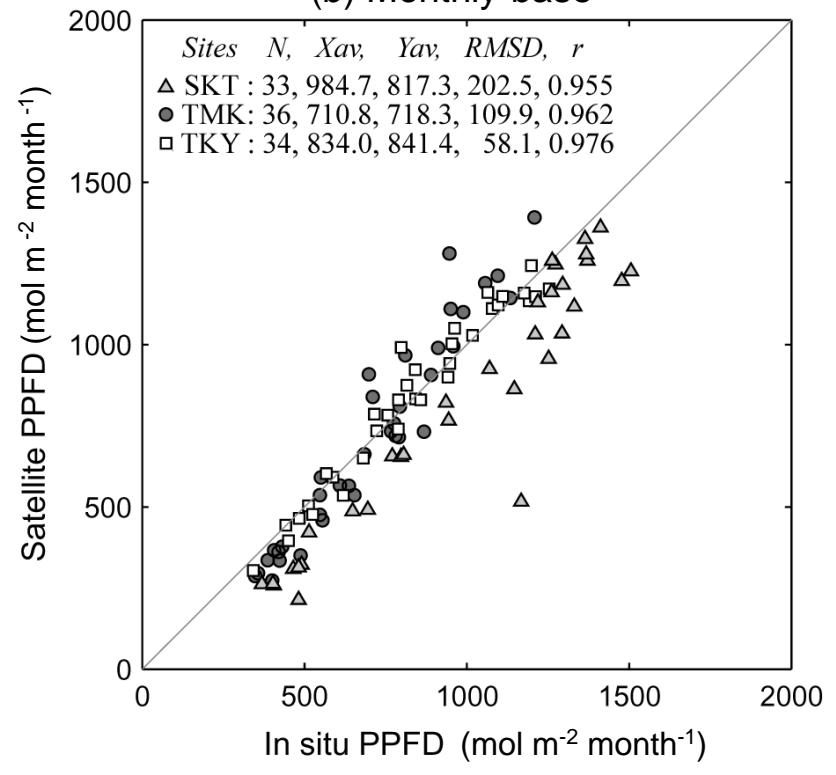

Fig. 2. Scatter plot between in situ and satellite monthly PPFD for (a) daily-base and for (b) monthly base. The triangle, circle, and square in Fig. 2b show samples at the SKT, TMK, and TKY sites. The sample number, average of in situ data (Xav), average of satellite data (Yav), RMSD, and correlation coefficients at each site are listed in the figure.

ations of the GPP in Asia using satellite-based data, and the monthly GPP was estimated for Asia in this study.

As inputs of SVM, we used ground observation data and satellite remote sensing data. The ground observation data include Rad and GPP at flux sites from Ameriflux Level 4 (gap-filled) weekly (8-day) data (available at: http: //public.ornl.gov/ameriflux/) and Asiaflux data (SKT, TMK, CBS, TKY, and QYZ; see Sect. 2.2). These data are used for (Eq. 1) the input of SVM (GPP and Rad) and (Eq. 2) model validation (GPP). Satellite remote sensing data include LST and EVI. Both are from an eight-day composite of the MODIS-based LST (Wan et al., 2002) and EVI (Huete et al., 2002) from 2000 to 2006. For the satellite-based GPP evaluation processes at the flux sites, we used MODIS 1-km resolution American Standard Code for Information Interchange (ASCII) subset datasets, each of which consisted of 7-by-7 km regions centered on the flux towers for LST and EVI (Cook et al., 2004). At each time step, we averaged these values using high-quality pixels by using the quality 


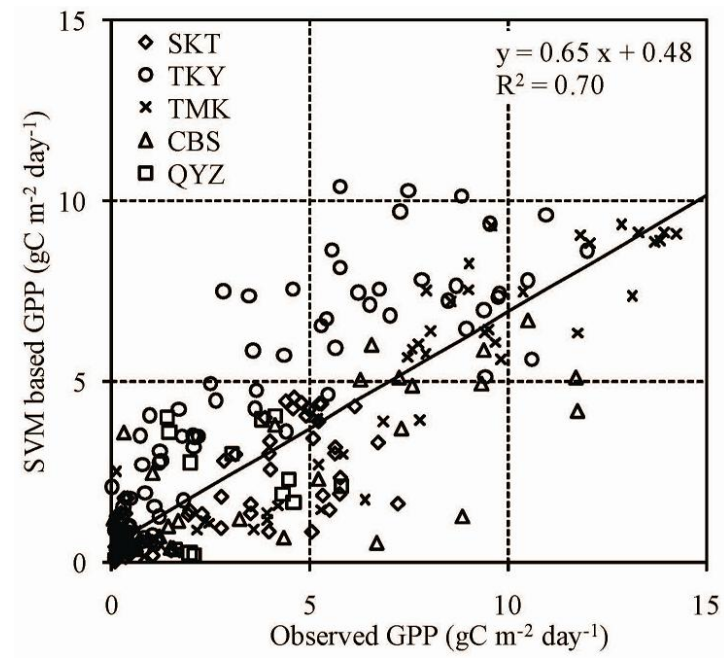

Fig. 3. Scatter plot between in situ GPP (Xav) and SVM-based GPP (Yav). Data is categorized by site (Table 1) using symbols.

assurance (QA) flag. For the spatial analysis, we created 8$\mathrm{km}$ spatial resolution data from MODIS LST and EVI; for data cleaning, all data were filled using averaged 8-day data calculated from 2001 to 2006 at each grid point if the QA flags were not satisfactory.

As a result of model training and testing, we obtained the SVM kernel parameters of $\mathrm{C}=1.072, \sigma=7.464$, and $\varepsilon=$ 0.203 with a coefficient of determination of $R^{2}=0.71$ and an RMSE of $2.33 \mathrm{gC} \mathrm{m}^{-2}$ day $^{-1}$ between the observed and satellite-based GPP (Fig. 3). Relatively better agreement was obtained at TKY, which could be related to the better estimation of insolation by satellite data (see Fig. 2a, b). On the other hand, values of satellite-based GPP at other sites were systematically lower than those of ground-based GPP, especially at TMK, SKT, and CBS. Although the reason has not been clarified yet, a possible explanation was that the model could not capture a very high in situ GPP, especially in the peak growing season in a larch forest at TMK (see Fig. 6). Larch forests almost uniquely exist in the northeast part of Eurasia (Koike et al., 2000), and cool-temperate larch forests have a photosynthetic efficiency that is significantly higher than that found in other forests of East Asia (Saigusa et al., 2008), which could make an accurate prediction difficult.

Overall, we obtained a similar $R^{2}$ value but a larger RMSE value than that reported by Yang et al. (2007), which was probably due to scales that were spatially broader than those from the original studies. Although the accuracy of the GPP estimation still needs to be improved, we consider that the spatio-temporal variability in GPP estimated by the SVM approach can be used in the present study.

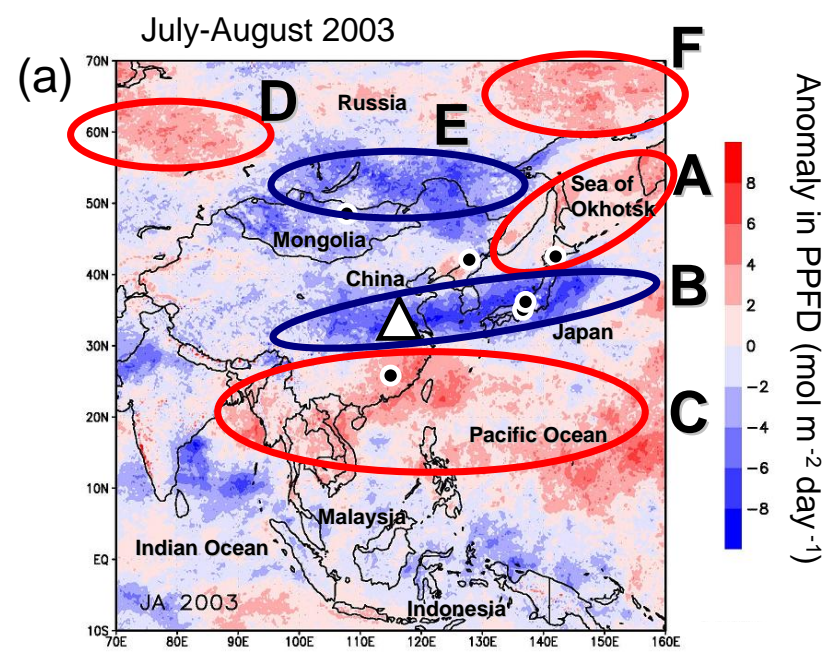

(base period 2001-2006)

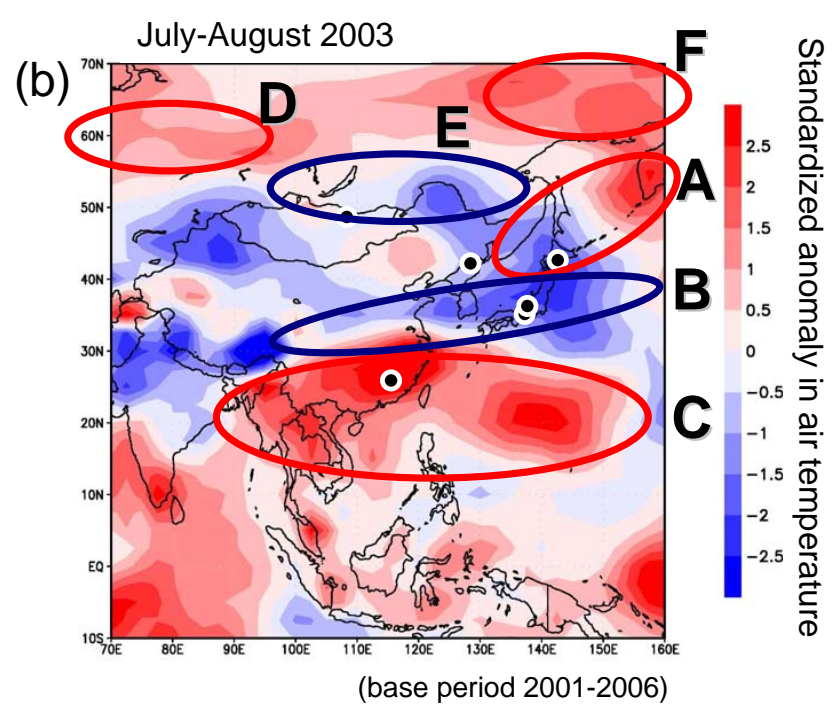

Fig. 4. Spatial distribution of (a) the anomaly in the summer PPFD and (b) the standard anomaly in the summer air temperature for 2month average of July-August in 2003 (base period 2001-2006). Black circles show the location of the study sites.

\section{Results and discussion}

\subsection{Spatial distribution of the PPFD anomaly in the 2003 summer}

Figure $4 \mathrm{a}$ shows the spatial distribution of the anomaly within the summer PPFD (2-month average of July-August) in 2003 estimated by satellite remote sensing data. The base period is 2001-2006. In Fig. 4a, the red area (positive anomaly in the PPFD) and the blue area (negative anomaly) appeared alternatively from north to south over eastern Eurasia. In East Asia, a significant negative PPFD anomaly was observed in a zonal area within a latitudinal range of 30 $40^{\circ} \mathrm{N}$ and a longitudinal range of $100-150^{\circ} \mathrm{E}$, extending 
from China to the main island of Japan through South Korea (the area indicated as a blue oval with the symbol "B" in Fig. 4a). The negative anomaly in the PPFD in the zonal area was induced by an active rain front which brought the early summer rainy season over the region and remained for an unusually long time from June to August 2003. This rain front caused floods in the Huai River basin in China (the area indicated by an open triangle in Fig. 4a) and a cool summer with extremely low radiation on the main island of Japan. On the other hand, the positive anomaly in the PPFD was observed to the north and the south of the front (the area indicated by red ovals with the symbols "A" and "C", respectively), and the weather was extremely hot and dry in southeastern China (the area included in " $C$ "). The anomalous pattern remained for two months.

According to the world meteorological observation reports (Japan Meteorological Agency, 2005), the anomalous weather patterns were observed in the insolation, air temperature, and precipitation not only in East Asia but also over a wide area in northern Eurasia, and the patterns appeared in June and ended in August 2003. To demonstrate the meteorological conditions of the 2003 summer, the spatial distribution of the standardized anomaly in the summer air temperature (2-month average of July-August) in 2003 is displayed in Fig. 4b. The data were obtained from NCEP/NCAR reanalysis data (Kistler et al., 2001), and the anomalies refer to the 2001-2006 base period. Figure 4b shows that the strong positive and negative anomalies in the air temperature agreed well with those in the PPFD (Fig. 4a) over a wide area in the Eurasian Continent especially in Russia (the area "D" and "F") and in southeast China (the area " $C$ "). On the other hand, the anomalies in the air temperature and PPFD were less clear in The Malay Archipelago, which includes Malaysia and Indonesia.

Recent studies suggested that the anomalous weather patterns observed from Europe to East Asia through Russia during the 2003 summer might be related to each other over large distances (Yamazaki, 2004; Ogi et al., 2005). Such anomalous atmospheric patterns linked together in distant regions (thousands of kilometers) are called teleconnections, and the phenomenon has been studied in terms of atmospheric dynamics (e.g., Limpasuvan and Hartmann, 1999; Yamazaki and Shinya, 1999; Kimoto et al., 2001; Nakamura and Fukamachi, 2004). Although the mechanisms of the extreme weather conditions in the 2003 summer have not been fully clarified, such meteorological phenomena will provide valuable information to estimate impacts of large-scale climatic disturbances on the terrestrial carbon cycle at continental scale.

\subsection{Meteorological conditions and GPP at ground observational sites in the 2003 summer}

To test the response of each forest site to the anomalous weather pattern in the 2003 summer, the values of the monthly precipitation and PPFD, the monthly mean daytime air temperature and daytime water vapor pressure deficit (VPD), and the monthly GPP are displayed in Fig. 5 for SKT, CBS, and QYZ (sites in Eurasia) and in Fig. 6 for TMK, TKY, and SMF (sites in the Japan Islands).

In a boreal larch forest at SKT, high values of PPFD ( $>1000$ mol month $^{-1}$ ) were observed for five months from April to August (Fig. 5b). However, the active growing season (GPP $>50 \mathrm{gC} \mathrm{m}^{-2} \mathrm{month}^{-1}$ ) was limited for a short period from June to August (Fig. 5e), corresponding with the period when the monthly mean daytime air temperature was higher than $10^{\circ} \mathrm{C}$ (Fig. 5c). A small amount of precipitation was observed during the growing season, mainly in July (Fig. 5a). The daytime VPD was less than $1.1 \mathrm{kPa}$ (Fig. 5d), suggesting that drought stress was not severe. Inter-annual variations of the PPFD, air temperature, and precipitation as well as the GPP were not obvious during the growing season.

The seasonal patterns of meteorological variables in a cool-temperate mixed forest at CBS were characterized by a short rainy season in July. High monthly precipitation $\left(>150 \mathrm{~mm} \mathrm{month}^{-1}\right)$ was observed in July (Fig. 5f), corresponding with a reduction in the PPFD (Fig. $5 \mathrm{~g}$ ) and the daytime VPD (Fig. 5i). The active growing season (GPP $>50 \mathrm{gC} \mathrm{m}^{-2}$ month $^{-1}$ ) was from May to September, with a gentle peak in the GPP from June to August (Fig. 5j). No clear year-to-year change in the GPP was observed in 2003 and 2004.

In a sub-tropical forest at QYZ, the characteristics of the seasonal changes in meteorology and GPP were considerably different from those in SKT and CBS. The whole year was the active growing season (GPP $>50 \mathrm{gC} \mathrm{m}^{-2}$ month $^{-1}$ ) (Fig. 5o). The monthly precipitation had double peaks, and there was a severe seasonal drought in mid-summer (Fig. 5k). The monthly values of the PPFD, daytime air temperature, and daytime VPD were much higher in July than in other months (Fig. 51-n). Specifically, in July 2003, an unusually high daytime VPD ( $2.7 \mathrm{kPa}$; Fig. $5 \mathrm{n})$ caused severe drought stress and a reduction in the GPP (Fig. 5o). The extremely hot and dry weather conditions in the 2003 summer and the effects on the ecosystem at QYZ have been found and described in detail in studies such as those by Sun et al. (2006), Wen et al. (2006), and Yu et al. (2008).

The seasonal patterns of the GPP estimated at three sites in the Japan Islands were characterized by more maritime climate with sufficient summer precipitation. In a cool-temperate larch forest at TMK, high monthly precipitation $\left(>150 \mathrm{~mm} \mathrm{month}^{-1}\right.$ ) was observed mainly from July to October (Fig. 6a) associated with a reduction in the PPFD (Fig. 6b) and the daytime VPD (Fig. 6d) especially in July and August. The daytime VPD was 


\section{Eurasian continent}

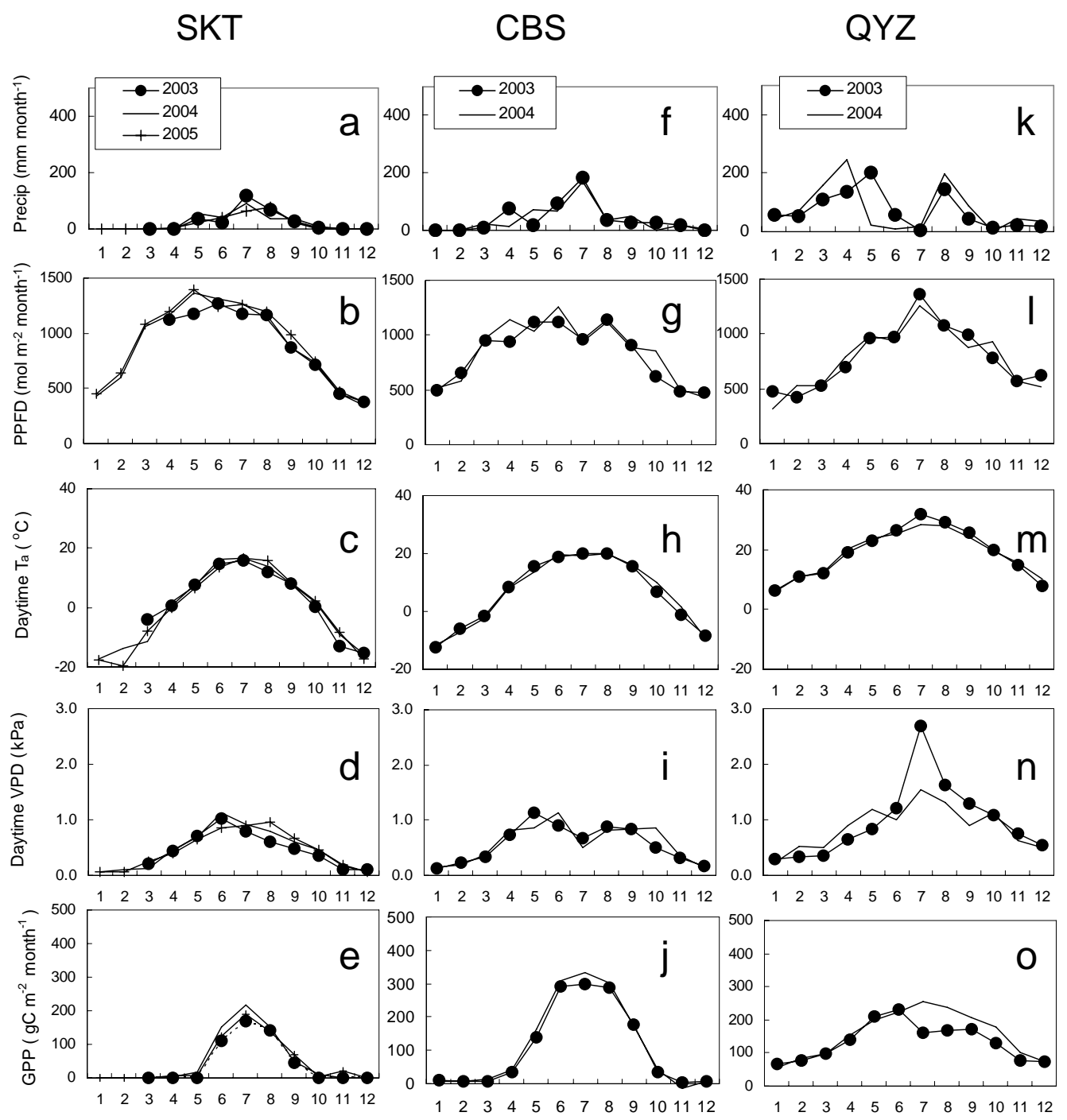

Fig. 5. Monthly meteorological conditions and GPP observed at the three sites listed in Table 1 for (a) SKT, (b) CBS, and (c) QYZ. The site code and year(s) of observation are indicated in each figure.

limited ( $<0.6 \mathrm{kPa}$; Fig. $6 \mathrm{~d})$, suggesting no critical drought stress on photosynthesis. The active growing season (GPP $>50 \mathrm{gC} \mathrm{m}^{-2}$ month $^{-1}$ ) was from May to October (Fig. 6e), and the maximum value of the GPP was observed in June. The summer weather, especially insolation, was variable in July and August (Fig. 6b), and the mid-summer GPP was mainly controlled by the PPFD. The monthly PPFD in July was 24\% higher in 2003 than in previous years (2001-2002) (Fig. 6b), which caused a 19\% higher GPP in July 2003 than in previous years (Fig. 6e). The positive PPFD anomaly in July 2003 was also seen in Fig. 4a in Hokkaido, a northern island of Japan (included in area "A").
In a cool-temperate birch-oak secondary forest at TKY, high monthly precipitation ( $>150 \mathrm{~mm}$ month $^{-1}$ ) was observed every season (Fig. 6f). The daytime VPD was limited for a whole year $(<0.6 \mathrm{kPa}$; Fig. $6 \mathrm{i})$, as at TMK. The active growing season (GPP $>50 \dot{\mathrm{gC} \mathrm{m}}{ }^{-2} \mathrm{month}^{-1}$ ) was from May to October (Fig. 6j). The year-to-year change in the GPP was obvious in July, and that was mainly affected by the PPFD. The weather in July 2003 was characterized by low temperature (Fig. 6h) and a low PPFD (Fig. 6g) under the influence of a mid-latitude rain front (the area "B" in Fig. 4a). The monthly PPFD in July was 32\% lower in 2003 than in previous years (2001-2002) (Fig. 6g), which caused a 26\% lower GPP in July 2003 than in previous years (Fig. 6j). 


\section{Japan Islands}

\section{$\begin{array}{lll}\text { TMK } & \text { TKY }\end{array}$}
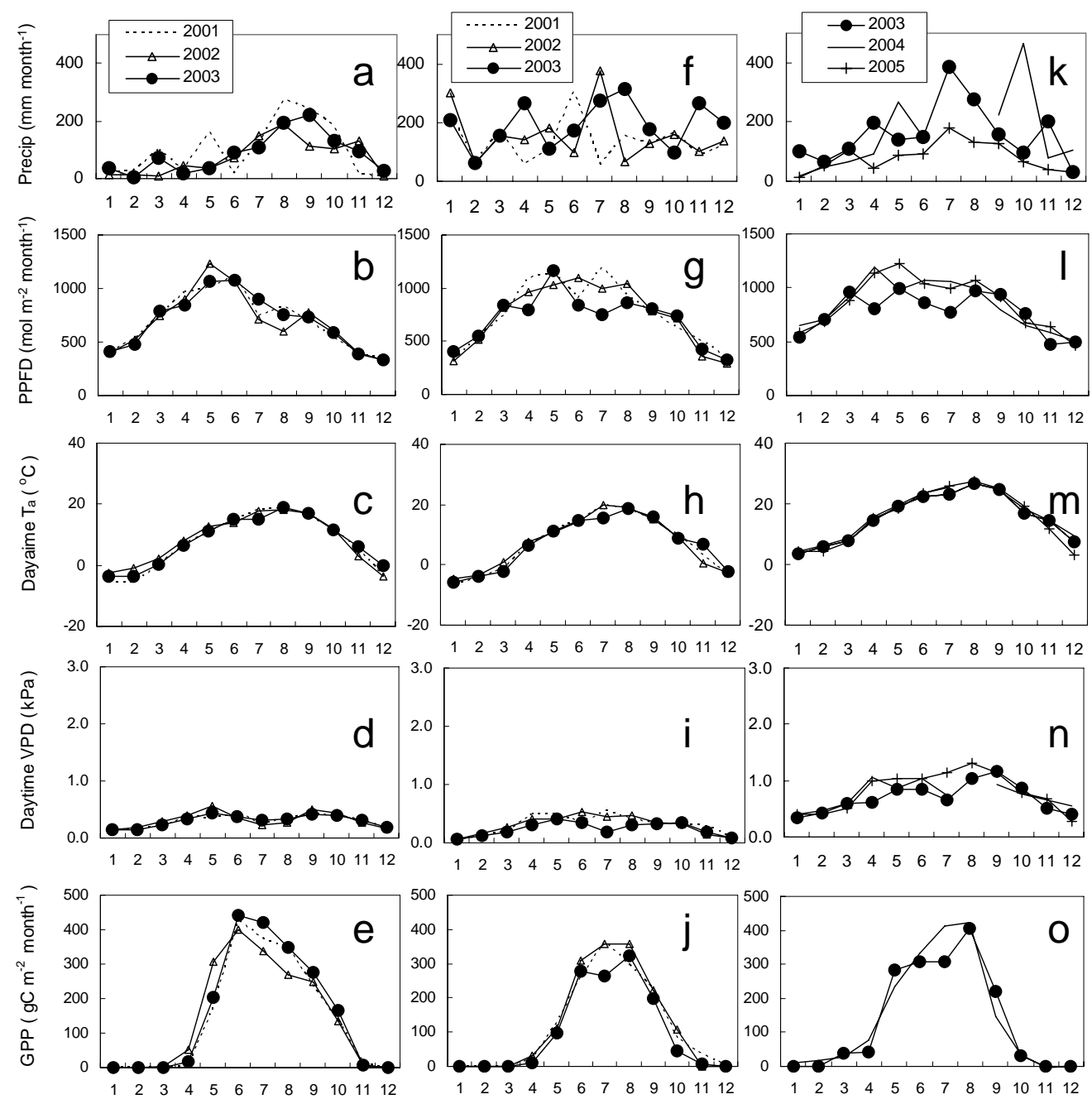

Fig. 6. Monthly meteorological conditions and GPP observed at the three sites listed in Table 1 for (a) TMK, (b) TKY, and (c) SMF. The site code and year(s) of observation are indicated in each figure.

In a warm-temperate mixed forest at SMF, high monthly precipitation (>150 $\mathrm{mm} \mathrm{month}^{-1}$ ) was observed from April to October (Fig. 6k). The active growing season (GPP $>50 \mathrm{gC} \mathrm{m}^{-2} \mathrm{month}^{-1}$ ) was from May to September (Fig. 6o). The year-to-year change in the GPP was obvious in July. The weather in July 2003 at SMF was influenced by the rain front, as it was at TKY, which caused a reduction in temperature and in the PPFD (Figs. 61, m). The monthly PPFD in July was 27\% lower in 2003 than in 2004 (Fig. 61), which caused a 26\% lower GPP in 2003 than in 2004 (Fig. 6o).
The overall results of the six ground observational sites are summarized as follows.

1. Under the influence of a long active rain front that brought the summer rainy season, the GPP in central Japan (TKY and SMF) was 20-30\% lower in the 2003 summer than in other years due to significant reduction in the PPFD.

2. The GPP in TMK (north of the rain front) was slightly more enhanced by a higher PPFD than that in normal years.

3. In Mongolia (SKT) and in northeastern China (CBS), the GPP in July 2003 differed little from that of other years. 


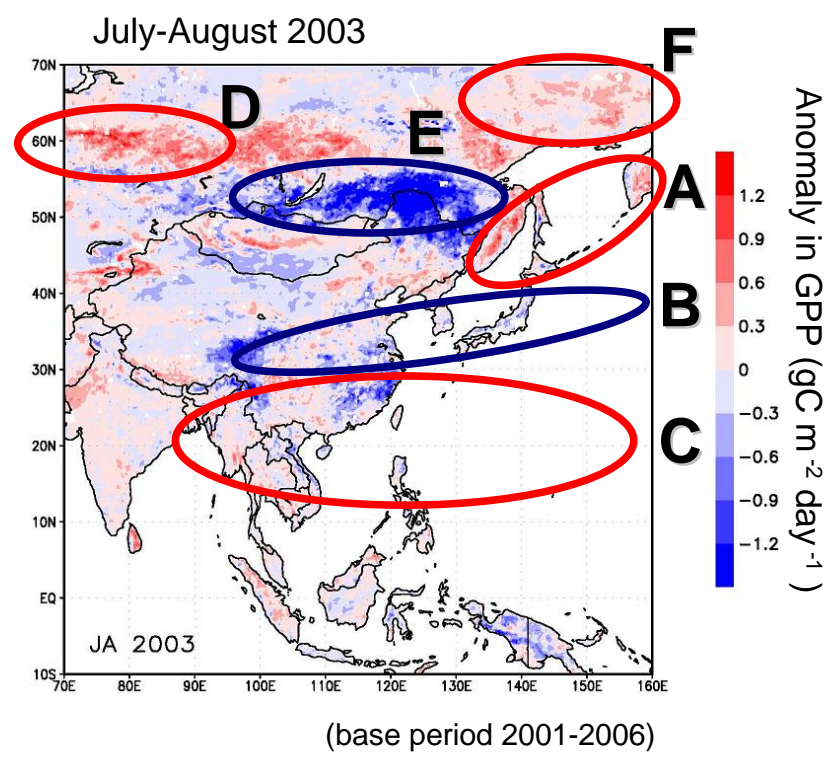

Fig. 7. Spatial distribution of the anomaly in summer GPP (2-month average of July-August) in 2003 (base period 2001-2006). The $95 \%$ confidence interval is $0.58 \mathrm{gC} \mathrm{m}^{-2} \mathrm{day}^{-1}$ for 2 -month average.

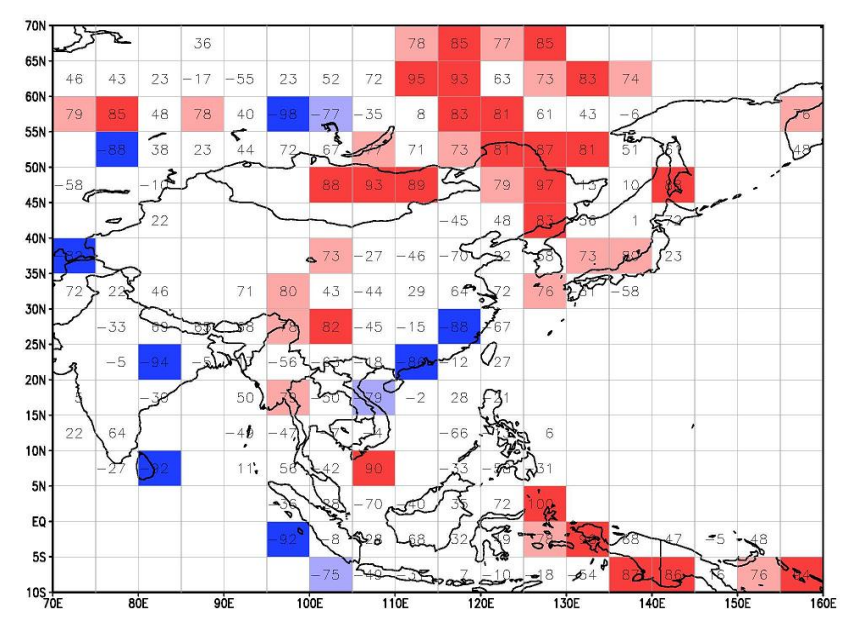

Fig. 8. Spatial distribution of the correlation coefficient between the year-to-year changes in the anomalies in the PPFD and GPP for mid-summer (2-month average of July-August). The numbers in the figure indicate the correlation coefficients multiplied by 100 . The dark and light colors mean the significance level of 0.05 and 0.1 , respectively.

4. In southeastern China, the GPP in QYZ (south of the rain front) was significantly reduced by severe drought stress in the summer 2003 due to unusually high insolation and high VPD.

\subsection{Spatial distribution of the GPP anomaly in the 2003 summer}

Figure 7 shows the spatial distribution of the anomaly within the summer GPP (2-month average of July-August) in 2003 estimated by the SVM approach. The base period is 20012006. The red area (positive anomaly in the GPP) and the blue area (negative anomaly) appeared from north to south over eastern Eurasia, similarly to those observed in the PPFD anomaly (Fig. 4a). In the higher latitudes $\left(>40^{\circ} \mathrm{N}\right)$, the spatial distribution of positive and negative anomalies in the GPP agreed well with that in the PPFD (Fig. 4a). The agreement was especially better in northern Japan, the Russian Far East, northern China, and Siberia (the area "A", "D", "E", and "F").

In the mid-latitude, the area of the negative anomaly in the GPP corresponded with that in the PPFD within a latitude range of $30-40^{\circ} \mathrm{N}$ from Japan to east China. The reduced PPFD by the active rain front decreased the GPP, as shown in the ground observational sites at TKY and SMF (Fig. 6j, o), respectively.

In the lower latitude, the responses of the GPP were different from those estimated in the mid- and high-latitudes. The negative anomaly in the GPP appeared in southeastern China (the area included in "C") under a significant positive anomaly in the PPFD. This result is explained as follows: the unusually high PPFD caused the high air temperature and high VPD, which brought severe drought stress in the region and decreased the GPP, as observed at QYZ. The limitation of the interpretations we have presented is that QYZ is a planted forest and is only one site clearly south of the rain band from $30-40^{\circ} \mathrm{N}$. We consider that the vegetation at QYZ was one of typical forests in this region, since the planted forest (mainly evergreen conifers) is the major component of forest in South China, which occupied more than half of the total planted forest area in China (Sun et al., 2006). However, more data are clearly necessary to improve the interpretation in the GPP anomalies especially in sub-tropical and tropical forest ecosystems.

\subsection{Spatial distribution of the correlation coefficient between year-to-year changes in the PPFD and GPP}

In this section, the degree of correlation was examined between the year-to-year changes in the PPFD anomaly and that in the GPP anomaly. The correlation coefficients are displayed in Fig. 8 to demonstrate the spatial distribution of essential controlling factors for the GPP. The focus was on the mid-summer (2-month average of July and August). The period of analysis was 2001-2006. The values of the correlation coefficients were estimated only for the forested area, and they were averaged over every 5-degree latitude and longitude tile. The red (or blue) colors indicate the area in which the year-to-year change in the GPP positively (or negatively) correlated with that in the PPFD. 
The areas of positive correlation between the GPP and PPFD appeared mainly in the mid- and high-latitudes $\left(>30^{\circ} \mathrm{N}\right)$ in the northeastern part of Eurasia (Japan, northeastern China, northern Mongolia, and eastern Siberia). The regions were dominated by cool-temperate and boreal forests, where the year-to-year change in the mid-summer GPP was essentially affected by meteorological anomalies associated with the PPFD anomaly. The influence of the summer drought was not critical because precipitation was sufficient during the growing season, as suggested at sites other than QYZ in Figs. 5 and 6.

On the other hand, areas of significant negative correlation appeared in southeastern China $\left(20-30^{\circ} \mathrm{N} ; 110-120^{\circ} \mathrm{E}\right)$. The region was mainly covered with evergreen sub-tropical forests, and the summer seasonal drought played an important role in the year-to-year change in the mid-summer GPP. These results were consistent with those obtained in the spatial distributions of anomalies in the PPFD and GPP for the 2003 summer (Figs. 4a and 7) and the results observed from a ground observational site (QYZ in Figs. 5 and 6).

Another interesting result was found in tropical forests around the equator $\left(10^{\circ} \mathrm{S}-10^{\circ} \mathrm{N}\right)$. Areas of significant positive correlation appeared in the east $\left(>125^{\circ} \mathrm{E}\right)$ close to the Pacific Ocean, while some areas of negative correlation existed in the west $\left(<105^{\circ} \mathrm{E}\right)$, close to the Indian Ocean. Although a seasonal change in the meteorological conditions is not obvious in the equatorial region compared with that in the mid- and high-latitudes, the mechanism of the year-toyear change is much more complicated. Several different dynamics of atmosphere-ocean interactions are involved in the inter-annual variations in the region, such as the Asian monsoon circulations and the ENSO events (Tian et al., 2003; Malhi and Wright, 2004), especially important in the Pacific coast, and the air-sea interactions and atmospheric circulations over the Indian Ocean (Kumar et al., 1999; Rajendran and Kitoh, 2008). The tropical forests in the regions are also extensively heterogeneous due to intense land use pressure and fires (Page et al., 2002; Huete et al., 2008). The spatial pattern in the different light-response of the GPP might be influenced by a different mechanism of inter-annual variability in the meteorological conditions and/or the land use and degradation of tropical forests.

Several studies have tried to clarify the degree of lightand water-limitations in the year-to-year variations of evapotranspiration and photosynthesis in the tropical Asian forests (Tanaka et al., 2004; Hirano et al., 2007; Huete et al., 2008); however, the ground datasets still fail to provide an understanding of the complexity of the region. Further studies are necessary to improve the estimation of the GPP in the area and to gain more knowledge of the spatial distribution of the controlling factors of the GPP.

\subsection{Implication for biological responses to future climate in the Asian monsoon region}

The datasets acquired in this study can be used to present the normal characteristics of the influence of an Asian monsoon climate as well as the anomalous conditions in 2003 in eastern Eurasia. In normal years, the seasonal movement of the rain front brings an early summer rainy season in East Asia, which is one of the most important meteorological events in the region. The rainy season starts in April or in May in the lower latitudes, such as in QYZ (Fig. 5k), and in June or in July in the mid-latitudes, such as in TKY and SMF (Fig. 6f, k). The rain front is weakened in the higher latitudes $\left(>40^{\circ} \mathrm{N}\right)$; then, only a short rainy period is observed in July at SKT and CBS (Fig. 5a, f). Finally, the rain band becomes less active or disappears in late summer.

These features may, however, be altered under future climatic conditions. Ongoing global warming may have the potential to increase the frequency and magnitude of many extreme events (Easterling et al., 2000). In East Asia, recent studies using climate prediction models suggested that the activity of the summer monsoonal rain band could be increased by strengthened cyclonic and anticyclonic atmospheric circulations (Kimoto, 2005). If the predictions are reliable, the frequency of anomalous weather conditions, such as those that occurred in 2003, may increase.

Studies based on terrestrial ecosystem models have suggested that anomalous weather patterns and their year-toyear variability substantially affected productivity in the Asian ecosystems (Tian et al., 2003). However, there are still enormous uncertainties in the estimation of the carbon budget in Asia within the terrestrial ecosystem models as well as from ground observational data. The data shortage and uncertainties are especially serious in sub-tropical and tropical regions. Studies are clearly necessary to gain more accurate estimations of the response of Asian ecosystems to large-scale meteorological phenomena and to enable the prediction of future climatic impacts based on efforts such as: data sharing among flux monitoring networks; developing and validating ecosystem models and remote sensing techniques, which are applicable to a variety of Asian ecosystems; and integrating analyses using multiple methods, such as ground observation, remote sensing, and models in relation to the large-scale carbon budget in Asia.

\section{Summary and Conclusions}

The $\mathrm{CO}_{2}$ uptake rates of several forest ecosystems in East Asia at various flux sites were compared during the anomaly period in the 2003 summer within different years and different latitudes. The GPP decreased significantly over the zonal area in the mid-latitude in East Asia under the influence of the Asian summer monsoon rain band, which remained for an unusually long period in the 2003 summer. To the north of 
the rain band, the GPP in a cool-temperate forest was slightly enhanced by a higher PPFD than that in normal years. On the contrary, the GPP was significantly reduced in the south of the band by a severe drought stress due to extremely hot and dry conditions in the summer 2003. The anomalous weather patterns in the 2003 summer were observed not only in East Asia but also over a wide area of northern Eurasia, and the anomalies were related to each other in terms of large-scale atmospheric circulations.

The spatial distributions of the year-to-year changes in the PPFD and GPP during mid-summer were examined during the study period from 2001 to 2006 . The spatiotemporal variation of the PPFD was obtained by satellite remote sensing data, and that of the GPP was derived by a regression-type model, which was evaluated and compared to ground observation data. The correlation between year-toyear changes in the PPFD and GPP was positive in the midand high latitudes since the incoming radiation was an essential controlling factor of the GPP in the regions. On the other hand, the PPFD and GPP were negatively correlated in the lower latitudes under the influence of severe drought stress caused by enhanced incoming radiation. Since it is possible that the frequency of anomalous summer weather conditions may be greater in the future and the anomalous weather patterns may affect productivity in the Asian terrestrial ecosystems, further studies are necessary to gain a more accurate understanding of the response of Asian ecosystems to the meteorological patterns.

This study showed a part of the feature of the response in East Asian ecosystems on the large-scale meteorological anomalous patterns in northern Eurasia in the 2003 summer. Although the result and the interpretation are limited, the data lead to an understanding of the spatial distribution of ecosystem responses to large-scale meteorological phenomena and serve as a verification dataset for the development of terrestrial ecosystem models.

Acknowledgements. This study was financially supported by the A3 Foresight Program (CarboEastAsia: Capacity building among ChinaFlux, JapanFlux, and KoFlux to cope with climate change protocols by synthesizing measurement, theory, and modeling in quantifying and understanding of carbon fluxes and storages in East Asia) by the Japan Society for the Promotion of Science (JSPS), the National Natural Science Foundation of China (NSFC), and the Korea Science and Engineering Foundation (KOSEF). The data were provided by CarboEastAsia database.

The authors would like to thank the project investigators, their coworkers, and students for providing data and valuable comments. Especially, L. Zhang (Institute of Geographic Sciences and Natural Resources Research, Chinese Academy of Sciences); Y. Takahashi, A. Ogawa, and S. Yuta (National Institute for Environmental Studies, Japan); H. Kondo, S. Murayama, and T. Maeda (National Institute of Advanced Industrial Science and Technology, Japan); K. Nasahara (University of Tsukuba, Japan); H. Muraoka (Gifu University, Japan); A. Kotani (Nagoya University, Japan); and G. Davaa and D. Oyunbaatar (Institute of Meteorology and
Hydrology, Mongolia). The authors also wish to thank all of the scientists and support staff at the AmeriFlux sites for providing data. The SVM software from LIBSVM (Chang and Lin, 2005) facilitated this study.

Edited by: J. Kim

\section{References}

Chang, C. C. and Lin, C. J.: LIBSVM - A library for Support Vector Machines, http://www.csie.ntu.edu.tw/ cjlin/libsvm/, 2005.

Ciais, P., Reichstein, M., Viovy, N., Granier, A., Ogee, J., Allard, V., Aubinet, M., Buchmann, N., Bernhofer, C., Carrara, A., Chevallier, F., De Noblet, N., Friend, A. D., Friedlingstein, P., Grünwald, T., Heinesch, B., Keronen, P., Knohl, A., Krinner, G., Loustau, D., Manca, G., Matteucci, G., Miglietta, F., Ourcival, J. M., Papale, D., Pilegaard, K., Rambal, S., Seufert, G., Soussana, J. F., Sanz, M. J., Schulze, E. D., Vesala, T., and Valentini, R.: Europe-wide reduction in primary productivity caused by the heat and drought in 2003, Nature, 437, 529-533, 2005.

Cook, R. B., Margle, S. M., Holladay, S. K., Heinsch, F. A., and Schaaf, C. B.: Subsets of remote sensing products for AmeriFlux sites: MODIS ASCII Subsets, AmeriFlux Annual Meeting, Boulder, CO, 2004.

Cristianini, N. and Shawe-Taylor, J.: An introduction to Support Vector Machines and other kernel-based learning methods, Cambridge, U.K., Cambridge Univ. Press, 2000.

De Fries, R. S., Hansen, M., Townshend, J. R. G., and Sohlberg, R.: Global land cover classifications at $8 \mathrm{~km}$ spatial resolution: The use of training data derived from Landsat imagery in decision tree classifiers, Int. J. Remote Sens., 19, 3141-3168, 1998.

Easterling, D. R., Meehl, G. A., Parmesan, C., Changnon, S. A., Karl, T. R., and Mearns, L. O.: Climate extremes: Observations, modeling, and impacts, Science, 289, 2068-2074, 2000.

Frouin, R. and Murakami, H.: Estimating photosynthetically available radiation at the ocean surface from ADEOS-II Global Imager data, J. Oceanography, 63, 493-503, 2007.

Guan, D.-X., Wu, J.-B., Zhao, X.-S., Han, S.-J., Yu, G.-R., Sun, X.-M., and Jin, C.-J.: $\mathrm{CO}_{2}$ fluxes over an old, temperate mixed forest in northeastern China, Agr. Forest Meteorol., 137, 138149, 2006.

Hirano, T., Hirata, R., Fujinuma, Y., Saigusa, N., Yamamoto, S., Harazono, Y., Takada, M., Inukai, K., and Inoue, G.: $\mathrm{CO}_{2}$ and water vapor exchange of a larch forest in northern Japan, Tellus, 55B, 244-257, 2003.

Hirano, T., Segah, H., Harada, T., Limin, S., June, T., Hirata, R., and Osaki, M.: Carbon dioxide balance of a tropical peat swamp forest in Kalimantan, Indonesia, Global Change Biol., 13, 412425, 2007.

Hirata, R., Hirano, T., Saigusa, N., Fujinuma, Y., Inukai, K., Kitamori, Y., Takahashi, Y., and Yamamoto, S.: Seasonal and interannual variations in carbon dioxide exchange of a temperate larch forest, Agr. Forest Meteorol., 147, 110-124, 2007.

Hirata, R., Saigusa, N., Yamamoto, S., Ohtani, Y., Ide, R., Asanuma, J., Gamo, M., Hirano, T., Kondo, H., Kosugi, Y., Li, S.-G., Nakai, Y., Takagi, K., Tani, M., and Wang, H.: Spatial distribution of carbon balance in forest ecosystems across East Asia, Agr. Forest Meteorol., 148, 761-775, 2008. 
Huete, A., Didan, K., Miura, T., Rodriguez, E. P., Gao, X., and Ferreira L. G.: Overview of the radiometric and biophysical performance of the MODIS vegetation indices, Remote Sens. Environ., 83, 195-213, 2002.

Huete, A. R., Restrepo-Coupe, N., Ratana, P., Didan, K., Saleska, S. R., Ichii, K., Panuthai, S., and Gamo, M.: Multiple site tower flux and remote sensing comparisons of tropical forest dynamics in Monsoon Asia, Agr. Forest Meteorol., 148, 748-760, 2008.

Ichii, K., Suzuki, T., Kato, T., Ito, A., Hajima, T., Ueyama, M., Sasai, T., Hirata, R., Saigusa, N., Ohtani, Y., and Takagi, K.: Multi-model analysis of terrestrial carbon cycles in Japan: reducing uncertainties in model outputs among different terrestrial biosphere models using flux observations, Biogeosciences Discuss., 6, 8455-8502, 2009,

http://www.biogeosciences-discuss.net/6/8455/2009/.

Japan Meteorological Agency: Report on Abnormal Weather 2005, 383 pp. (in Japanese). http://www.data.kishou.go.jp/climate/ cpdinfo/climate_change/2005/pdf/2005_all.pdf, 2005.

Kadomura, H.: Climate anomalies and extreme events in Africa in 2003, including heavy rains and floods that occurred during northern hemisphere summer, African Study Monographs, Suppl. 30, 165-181, 2005.

Kato, T., Tang, Y., Gu, S., Hirota, M., Du, M. Y., Li, Y. N., and Zhao, X. Q.: Temperature and biomass influences on interannual changes in $\mathrm{CO}_{2}$ exchange in an alpine meadow on the QinghaiTibetan Plateau, Global Change Biol., 12, 1285-1298, 2006.

Kimoto, M.: Simulated change of the East Asian circulation under global warming scenario, Geophys. Res. Lett., 32, L16701, doi:10.1029/2005GL023383, 2005.

Kimoto, M., Jin, F.-F., Watanabe, M., and Yasutomi, N.: Zonaleddy coupling and a neutral mode theory for the Arctic Oscillation, Geophys. Res. Lett., 28, 737-740, 2001.

Kistler, R., Kalnay, E., Collins, W., Saha, S., White, G., Woollen, J., Chelliah, M., Ebisuzaki, W., Kanamitsu, M., Kousky, V., Van Den Dool, H., Jenne, R., Fiorino, M.: The NCEP-NCAR 50-year reanalysis: monthly means CD-ROM and documentation, Bull. Am. Meteorol. Soc., 82, 247-267, 2001.

Kitoh, A. and Uchiyama, T.: Changes in onset and withdrawal of the East Asian summer rainy season by multi-model global warming experiments, J. Meteor. Soc. Japan, 84, 247-258, 2006.

Kitoh, A., Yukimoto, S., Noda, A., and Motoi, T.: Simulated changes in the Asian summer monsoon at times of increased atmospheric $\mathrm{CO}_{2}$, J. Meteor. Soc. Japan, 75, 1019-1031, 1997.

Koike, T., Yazaki, K., Funada, R., Maruyama, Y., Mori, S., and Sasa, K.: Forest health and vitality in northern Japan: A history of larch plantation, Res. Notes, Fac. Forest., Univ. Joensuu, 92, 49-60, 2000.

Kumar, K. K., Rajagopalan, B., and Cane, M. A.: On the weakening relationship between the Indian monsoon and ENSO, Science, 284, 2156-2159, 1999.

Kusunoki, S.: Cool summer over Japan in 2003, Meteorological Research Note, 201, Meteorological Society of Japan, 199 pp., (in Japanese), 2005.

Levinson, D. H. and Waple A. M.: State of the Climate in 2003, Bulletin of the American Meteorological Society, 85, doi:10.1175/BAMS-85-6-Levinson, 2004.

Li, S.-G., Asanuma, J., Kotani, A., Eugster, W., Davaa, G., Oyunbaatar, D., and Sugita, M.: Year-round measurements of net ecosystem $\mathrm{CO}_{2}$ flux over a montane larch forest in Mongolia, J.
Geophys. Res., 110, D09303, doi:10.1029/2004JD005453, 2005.

Limpasuvan, V. and Hartmann, D. L.: Eddies and the annular modes of climate variability, Geophys. Res. Let., 26, 3133-3136, 1999.

Liu, J., Wang, L., and Wang, J.: Huai River flood in 2003 and its forecasting, prediction, and dispatching, Technical Note of National Institute for Land and Infrastructure Management, 211, 714, 2004

Lloyd, J. and Taylor, J. A.: On the temperature dependence of soil respiration, Funct. Ecol., 8, 315-323, 1994.

Luterbacher, J., Dietrich, D., Xoplaki, E., Grosjean, M., and Wanner, H.: European seasonal and annual temperature variability, trends, and extremes since 1500, Science, 303, 1499-1503, 2004.

Malhi, Y. and Wright, J.: Spatial patterns and recent trends in the climate of tropical rainforest regions, Phil. Trans. Roy. Soc. Lond. B Biol. Sci., 359, 311-329, 2004.

Matsumoto, J.: The seasonal changes in Asian and Australian monsoon regions, J. Meteor. Soc. Japan, 70, 257-273, 1992.

Matsumoto, K., Ohta, T., Nakai, T., Kuwada, T., Daikoku, K., Iida, S., Yabuki, H., Kononov, A. V., van der Molen, M. K., Kodama, Y., Maximov, T. C., Dolman, A. J., and Hattori, S.: Responses of surface conductance to forest environments in the Far East, Agr. Forest Meteorol., 148, 1926-1940, 2008a.

Matsumoto, K., Ohta, T., Nakai, T., Kuwada, T., Daikoku, K., Iida, S., Yabuki, H., Kononov, A. V., van der Molen, M. K., Kodama, Y., Maximov, T. C., Dolman, A. J., and Hattori, S.: Energy consumption and evapotranspiration at several boreal and temperate forests in the Far East, Agr. Forest Meteorol., 148, 1978-1989, 2008b.

Meehl, G. A. and Arblaster, J. M.: Mechanisms for projected future changes in south Asian monsoon precipitation, Clima. Dynam., 21, 659-675, 2003.

Meehl, G. A. and Washington, W. M.: South Asian summer monsoon variability in a model with doubled atmospheric carbon dioxide concentration, Science, 260, 1101-1104, 1993.

Nakamura, H. and Fukamachi, T.: Evolution and dynamics of summertime blocking over the Far East and the associated surface Okhotsk high, Q. J. Roy. Meteor. Soc., 130, 1213-1233, 2004.

Ogi, M., Yamazaki, K., and Tachibana, Y.: The summer northern annular mode and abnormal summer weather in 2003, Geophys. Res. Lett., 32, L04706, doi:10.1029/2004GL021528, 2005.

Ohtani, Y., Saigusa, N., Yamamoto, S., Mizoguchi, Y., Watanabe, T., Yasuda, Y., and Murayama, S.: Characteristics of $\mathrm{CO}_{2}$ fluxes in cool-temperate coniferous and deciduous broadleaf forests in Japan, Phyton, 45, 73-80, 2005.

Page, S. E, Siegert, F., Rieley, J. O., Boehm, H. D., Jaya, A., and Limin, S.: The amount of carbon released from peat and forest fires in Indonesia during 1997, Nature, 420, 61-65, 2002.

Rajendran, K. and Kitoh, A.: Indian summer monsoon in future climate projection by a super high-resolution global model, Current Science, 95, 1560-1569, 2008.

Saigusa, N., Yamamoto, S., Hirata, R., Ohtani, Y., Ide, R., Asanuma, J., Gamo, M., Hirano, T., Kondo, H., Kosugi, Y., Li, S.-G., Nakai, Y., Takagi, K., Tani, M., and Wang, H.: Temporal and spatial variations in the seasonal patterns of $\mathrm{CO}_{2}$ flux in boreal, temperate, and tropical forests in East Asia, Agr. Forest Meteorol., 148, 700-713, 2008.

Saigusa, N., Yamamoto, S., Murayama, S., and Kondo, H.: Interannual variability of carbon budget components in an AsiaFlux forest site estimated by long-term flux measurements, Agr. For- 
est Meteorol., 134, 4-16, 2005.

Saigusa, N., Yamamoto, S., Murayama, S., Kondo, H., and Nishimura, N.: Gross primary production and net ecosystem production of a cool-temperate deciduous forest estimated by the eddy covariance method, Agr. Forest Meteorol., 112, 203-215, 2002.

Sun, X., Wen, X., Yu, G., Liu, Y., and Liu, Q.: Seasonal drought effects on carbon sequestration of a mid-subtropical planted forest of southeastern China, Science in China Series D, 49, (Suppl. II), 110-118, 2006.

Tanaka, K., Takizawa, H., Kume, T., Xu, J., Tantasirin, C., and Suzuki, M.: Impact of rooting depth and soil hydraulic properties on the transpiration peak of an evergreen forest in northern Thailand in the late dry season, J. Geophys. Res., 109, D23107, doi:10.1029/2004JD004865, 2004.

Thornley, J. H. M.: Mathematical Models in Plant Physiology, Academic Press, London, 318 pp., 1976.

Tian, H., Melillo, J. M., Kicklighter, D. W., Pan, S., Liu, J., McGuire, A. D., and Moore III, B.: Regional carbon dynamics in monsoon Asia and its implications for the global carbon cycle, Global Planet. Change, 37, 201-217, 2003.

Tian, S.-F. and Yasunari, T.: Climatological aspects and mechanism of spring persistent rains over central China, J. Meteor. Soc. Japan, 76, 57-71, 1998.

Wan, Z., Zhang, Y., Zhang, Q, and Li, Z.: Validation of the landsurface temperature products retrieved from Terra Moderate Resolution Imaging Spectroradiometer data, Remote Sens. Environ., 83, 163-180, 2002.

Wen, X.-F., Yu, G.-R., Sun, X.-M., Li, Q.-K., Liu, Y.-F., Zhang, L.-M., Ren, C.-Y., Fu, Y.-L., and Li, Z.-Q.: Soil moisture effects on the temperature dependence of ecosystem respiration in a subtropical Pinus plantation of southeastern China, Agr. Forest Meteorol., 137, 166-175, 2006.

Yamazaki, K.: Arctic oscillation, Meteorological Research Note, 206, Meteorological Society of Japan, 181 pp., (in Japanese), 2004.
Yamazaki, K. and Shinya, Y.: Analysis of the Arctic Oscillation simulated by AGCM, J. Meteor. Soc. Japan, 77, 1287-1298, 1999.

Yang, F., Ichii, K., White, M. A., Hashimoto, H., Michaelis, A. R., Votava, P., Zhu, A. X., Huete, A., Running, S. W., and Nemani, R. R.: Developing a continental-scale measure of gross primary production by combining MODIS and AmeriFlux data through Support Vector Machine approach, Remote Sens. Environ., 110, 109-122, 2007.

Yang, F., White, M., Michaelis, A., Ichii, K., Hashimoto, H., Votava, P., Zhu, A. X., and Nemani, R. R.: Prediction of continental scale evapotranspiration by combining MODIS and AmeriFlux data through Support Vector Machine, IEEE T, Geosci. Remote. Sens., 44, 3452-3461, 2006.

Yoshikawa, C., Kawamiya, M., Kato, T., Yamanaka, Y., and Matsuno, T.: Geographical distribution of the feedback between future climate change and the carbon cycle, J. Geophys. Res., 113, G03002, doi:10.1029/2007JG000570, 2008.

Yoshino, M.: Four stages of the rainy season in early summer over East Asia (Part I), J. Meteor. Soc. Japan, 43, 231-245, 1965.

Yoshino, M.: Four stages of the rainy season in early summer over East Asia (Part II), J. Meteor. Soc. Japan, 44, 209-217, 1966.

Yu, G.-R., Wen, X.-F., Sun, X.-M., Tanner, B. D., Lee, X. H., and Chen, J.-Y.: Overview of ChinaFLUX and evaluation of its eddy covariance measurement, Agr. Forest Meteorol., 137, 125-137, 2006.

Yu, G.-R., Zhang, L.-M., Sun, X.-M., Fu, Y.-L., Wen, X.-F., Wang, Q.-F., Li, S.-G., Ren, C.-Y., Song, X., Liu, Y.-F., Han, S- J., and Yan, J.-H.: Environmental controls over carbon exchange of three forest ecosystems in eastern China, Global Change Biol., 14, 2555-2571, 2008.

Zhang, J.-H., Han, S.-J., and Yu, G.-R.: Seasonal variation in carbon dioxide exchange over a 200-year-old Chinese broad-leaved Korean pine mixed forest, Agr. Forest Meteorol., 137, 150-165, 2006. 